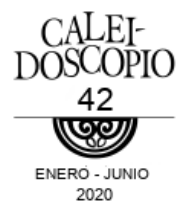

Reseñas

\title{
Reseña de Melchor (2017) Temporada de Huracanes
}

Review of Melchor (2017) Temporada de Huracanes

MARÍA ISABEL CABRERA MANUEL ${ }^{1}$

Melchor, Fernanda (2017).

Temporada de huracanes.

Ciudad de México: Penguin Random House.

Cuando me enteré de la publicación de esta novela, los comentarios al respecto eran todos elogios y recomendaciones. Lo anterior, sumado a la calidad narrativa por la que era conocida la autora tras la publicación de sus primeras novelas ${ }^{2}$, hizo que la primera edición se agotara con velocidad y que, a un año de la publicación del libro, se publicaron una, dos, tres, cuatro y hasta ahora siete reimpresiones. Me costó un poco de trabajo hacerme de un ejemplar, pero finalmente tengo uno de la cuarta reimpresión. Me costó mucho más trabajo hacerme al ánimo de leer, pues la temática de la misma, se sabe, dista muchísimo de ser edificante y en ese

\section{1 maiscam.83@gmail.com}

${ }^{2}$ Aquí no es Miami y Falsa liebre, ambas de 2013. 
momento me encontraba saturada de lecturas e información sobre violencia.

Afortunadamente, la curiosidad mata al gato y el libro no pasó mucho tiempo en el estante de las lecturas pendientes antes de que, por fin, lo leyera. Seguramente ya se han hecho muchas analogías acerca del título y el poder devastador de la obra. Pero no puedo dejar de reiterar lo que la novela genera, porque es de un nivel de honestidad que hasta en el título se confirma: es un huracán. Desde un inicio-y no me refiero a las primeras páginas, sino a las primeras palabras-se presenta como un viento aparentemente inofensivo pero persistente, que no deja que nada se asiente o esté "en paz", para después atrapar a quien lee en un malestar vertiginoso y una atracción irremediable de las que es imposible evadirse. Los huracanes se forman con choques de fuerzas que se oponen, temperaturas, corrientes contrarias que se encuentran: así, el libro se construye de manera lo mismo sutil que alarmante, de la confrontación y tensión permanente entre horror y deseo.

Pocas veces leo un libro "de un tirón" porque además de que el tiempo disponible lo dificulta, prefiero leer con calma. Pero los huracanes no dan tiempo, por lo que ni una ni otra cosa importó cuando comencé la lectura que, en parte por el estilo narrativo, en parte por lo avasallador de lo que ahí se relata, no permitió prácticamente hacer pausas. La tragedia no espera, se presenta con la contundencia de lo que reconocemos como insalvable, que queda oscilando entre la resignación y el poético esfuerzo de resistencia.

Las frases que se agolpan una tras otra, prácticamente sin pausas, sin puntos que permitan tomar aire, distancia, tiempo, amarran los ojos a las páginas que pasan y pasan tan irremediablemente como los hechos (entre realidad y 
ficción) que se narran y que tienen como centro de la acción a "La Matosa" una comunidad, como tantas del país, marcada por las violencias de Estado que como señala Pilar Calveiro3, engloban de manera indistinguible al crimen organizado y las estrategias de control del Estado como motor del horrorismo contemporáneo. Atestiguamos así, a través de la escritura de Melchor, una serie de sucesos que engarzan las vidas individuales a un contexto colectivo en el que difícilmente podríamos discernir una causa determinante, un primer motor que permitiera explicar de manera unívoca el sentido del padecimiento general que impregna la obra.

La calma pues, no es algo que se encuentre en las páginas del libro, porque tal como las sensaciones olfativas que produce el mismo y de las que está plagado, incluso en esos contados momentos de efímero sosiego y regocijo que viven los personajes, ellos y nosotros sabemos que no dura la calma y que sólo es preámbulo de la tormenta, que se anuncia como un hedor persistente que provoca el malestar sostenido que enturbia la psique de todos los habitantes de la Matosa y sus rededores.

La novela se compone de ocho apartados en los que los personajes se van abriendo paso, tomando forma, reclamando el reconocimiento de su existencia en un mundo que los niega al tiempo que se vale de sus fuerzas y voluntades para persistir. La Bruja, la Lagarta, Munra, Norma, Luismi y el Brando, junto con otros personajes que en momentos son presencias completamente corpóreas, a veces apenas sombras, ven entrelazados sus destinos en un delicado equilibrio de voluntades y fortuna, sumergidos en un contexto que enmarca su tragedia y que, como tal, no por dolorosa deja de ser una constante afirmación, una

${ }^{3}$ Calveiro, Pilar, Violencias de Estado, Siglo XXI, Buenos Aires, 2012.

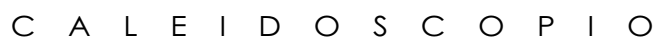


apuesta por la vida. Esas vidas son las que acompañamos en la lectura, aunque sea sólo un atisbo, vamos viendo cómo se delinean los caminos de adultos, niñas, adolescentes que se verán enfrentados para subsistir, con y por su circunstancia. Desde la problemática de la drogadicción, pasando por el abuso sexual a menores, la misoginia, la discriminación, la homofobia, la pobreza, hasta el narcotráfico y la corrupción, la novela logra ser un termómetro no reduccionista de las problemáticas que, en su conjunto, dan cuenta del estado de nuestra sociedad.

Temporada de huracanes de Fernanda Melchor es, en muchos sentidos, un libro excepcional. Es notable por su honestidad, por su valor literario y narrativo, por la forma cruda, pero cargada de sensibilidad, sin el edulcorante de la condescendencia con la que la autora construye la historia. Es un libro que sabe retratar, desde una óptica vertiginosa, sofocante, la realidad trágica de nuestro país y de las vidas concretas que lo conforman, que sin ser una lectura moralizante, obliga a sus lectores a salir del cinismo y la indiferencia al situarnos en la mente de quienes más la padecen. Es pues, una tragedia en el mejor de los sentidos, no esa centrada en el héroe y la narrativa épica con la que desafía a su destino, sino la de las personas anónimas, sin linajes notables ni personalidades grandilocuentes, pero con vidas tan desgarradoras y reales que harían palidecer a los héroes trágicos de las epopeyas a las que nos hemos acostumbrado.

El viento cruzaba la llanura y revolvía las hojas de los almendros en las copas y formaba remolinos de arena entre las tumbas distantes. Ya viene el agua, le contó el abuelo a los muertos, mientras contemplaba con alivio las nubes gordas que tupían el cielo. Bendito sea, ya viene el agua, repitió, pero ustedes no teman (p. 221). 
Me sumo así a los elogios que se hacen de la obra, pero sobre todo a la recomendación de leerla, porque la escritura de Melchor es una muestra de cuidado a esas vidas que hay que nombrar y a ese cuidado hay que sumarse aunque-tan frecuentemente que lastima-el llamado no haga eco de un nombre.

CÓMO CITAR ESTA RESEÑA

Cabrera Manuel, M. I. (2020). Reseña de Melchor (2017)

Temporada de Huracanes. Caleidoscopio - Revista Semestral de Ciencias Sociales y Humanidades, 23(42), 303-307.

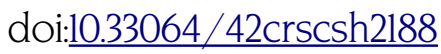

